\title{
Casa do forno: Saber popular e produção familiar de farinha de coco
}

\author{
Adelson da Cruz ${ }^{1}$ \\ Georgina Negrão Kalife Cordeiro²
}

Na comunidade rural de Anoirá, localizada aproximadamente a 12 km de Augusto Correa-Pará, encontra-se a tradição de produzir farinha de coco e beiju de massa a partir do manuseio da mandioca, especialmente no período de "Semana Santa". É uma atividade tipicamente familiar por envolver técnicas artesanais de fabricação, utilização de trabalho manual e empregabilidade de saberes empíricos sobre as diversas etapas de produção.

A "Casa do Forno", "Casa de Forno" ou "Casa de Farinha", são denominações que a comunidade utiliza para caracterizar o espaço da produção, lugar onde os trabaIhadores aplicam saberes de experiência feito ${ }^{3}$ para manusear instrumentos artesanais: tipitis, peneiras, sarilho, rodo, forno, terçados, machado. Nessa relação entre aplicabilidade de saberes e o manuseio de instrumentos artesanais, existe um processo prático de transmissão de conhecimentos, ou seja, é necessário que o trabalhador saiba escoIher a espécie útil para a produção, preparar a massa de mandioca, prensar para retirar o tucupi, peneirar, organizar a lenha manuseando machado, escolher o coco seco, retirar sua massa.

A Casa de Forno, portanto, é um espaço de ecologia de saberes onde está inserido um sistema produtivo que tem caráter artesanal, baseado na utilização e transmissão de conhecimentos empíricos por gerações de trabalhadores. (SANTOS, 2010). Mesmo que esses saberes sejam utilizados para melhorar a produção destas famílias, Xavier e

\footnotetext{
${ }^{1}$ Mestrando do Programa de Pós-Graduação em Linguagens e Saberes na Amazônia. Pedagogo. Especialista em Educação de Jovens e Adultos com ênfase em Juventude. Professor pesquisador do Grupo Universitário de Educação e Alfabetização de Jovens e Adultos (GUEAJA) e da Cátedra Paulo Freire na Amazônia.ddcameta@yahoo.com.br

${ }^{2}$ Docente da Faculdade de Educação do Instituto Ciências da Educação da Universidade Federal do Pará e Professora do Programa de Pós Graduação Linguagens e Saberes na Amazônia, vinculado ao Campus de Bragança/UFPA. Compõe a Comissão Pedagógica Nacional do Programa Nacional de Educação na Reforma Agrária - PRONERA e coordena o Centro de Documentação e Memória em Educação de Jovens e Adultos na Amazônia. Coordenadora do Grupo Universitário de Educação e Alfabetização de Jovens e Adultos (GUEAJA). cordeiro@ufpa.br

${ }^{3}$ Paulo Freire utiliza o termo para designar os saberes de práticas cotidianas. Esse conceito pode ser encontrado no livro Pedagogia da Autonomia: saberes necessários a formação docente.
} 
Flor (2015) alertam que, a Ciência cartesiana trata-os como desvalorizados já que não são validados pela academia e considera-os "à margem das instituições formais". As próprias autoras enfatizam que esses saberes são produzidos de forma solidaria por grupos específicos obtidos através de práticas cotidianas do mundo do trabalho e transmitidos de geração em geração, principalmente por meio da linguagem oral, de gestos e atitudes. Ou seja, os sujeitos envolvidos neste processo produtivo estão envoltos a procedimentos de ensino-aprendizagem caracterizados a partir da subjetividade existentes nas relações de trabalho estabelecido na Casa de Forno.

Assim, verifica-se que na produção de farinha de coco e beiju de massa existe um processo histórico de acumulação de saberes que se mantem, sobretudo por meio da organização do trabalho coletivo dos núcleos familiares que através da produção familiar conseguiram, mesmo que de forma não intencional, preservar as técnicas artesanais de produção e preservar a memória coletiva das gerações passadas. Destaca-se que, "por respeito" a Semana que esses produtores consideram "Santa", utilizam a quartafeira para fabricar seus produtos, pois acreditam que quinta e sexta-feira são dias para professarem sua fé e descansar.

As ações desenvolvidas na Casa de Forno, coloca-se na lógica do trabalho coletivo, onde todos os envolvidos tendem a desenvolver atividades variadas: retirar e ralar o coco seco, rachar com um machado a lenha, amassar a mandioca mole para transformar em massa, secá-la no sarilho através de tipiti, peneirar, lavar o forno, ou seja, todas são etapas que envolvem saberes populares e trabalho coletivo.

\section{Referências}

SANTOS, Boaventura de Sousa. Epistemologia do Sul. Cortez, São Paulo, 2010. XAVIER, Patrícia Maria Azevedo \& FLÔR, Cristhiane Carneiro Cunha. Saberes Populares e Educação Científica: Um olhar a partir da literatura na área de ensino de ciências. Revista Ensaio, Belo Horizonte, 2015. 


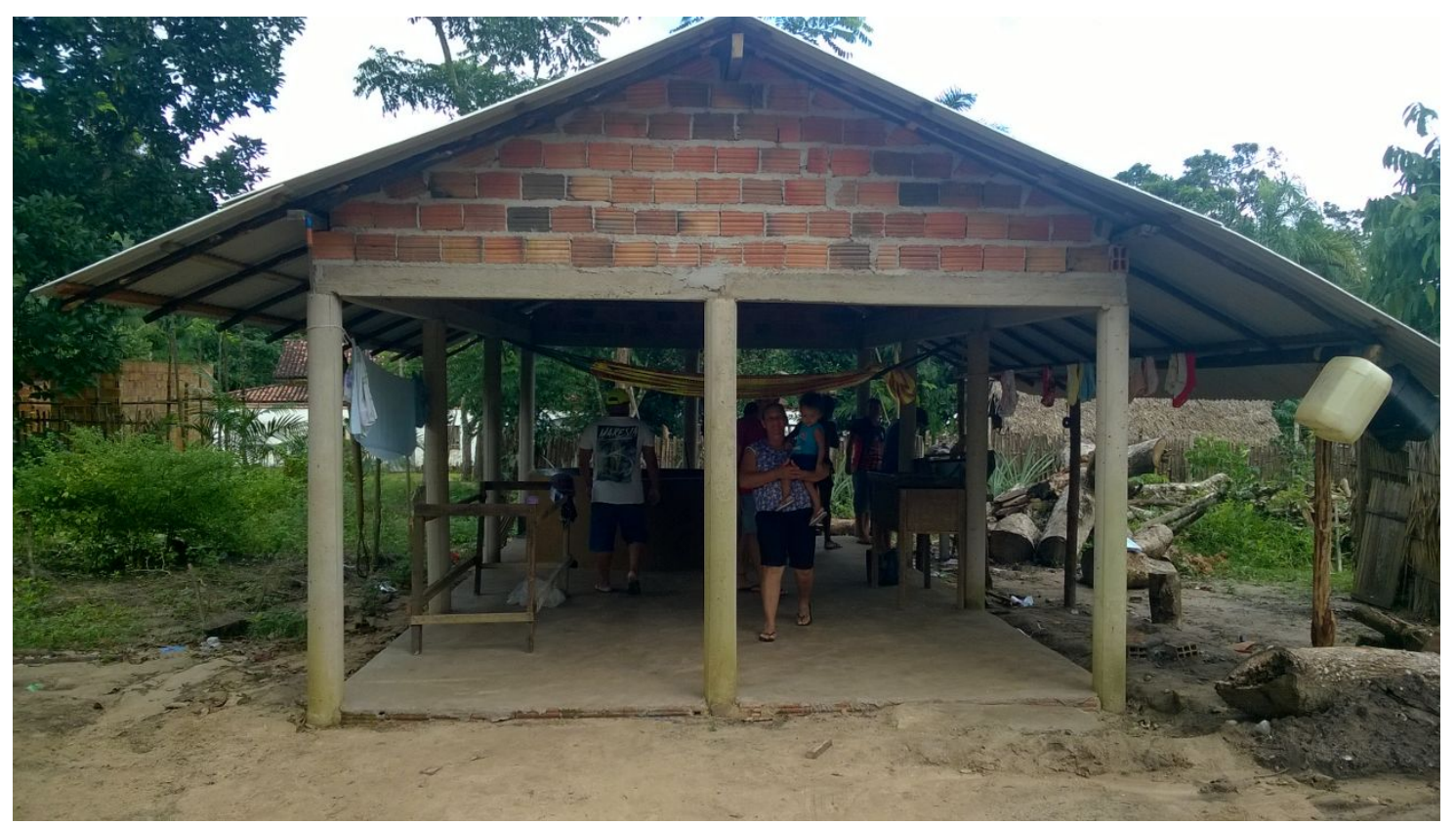




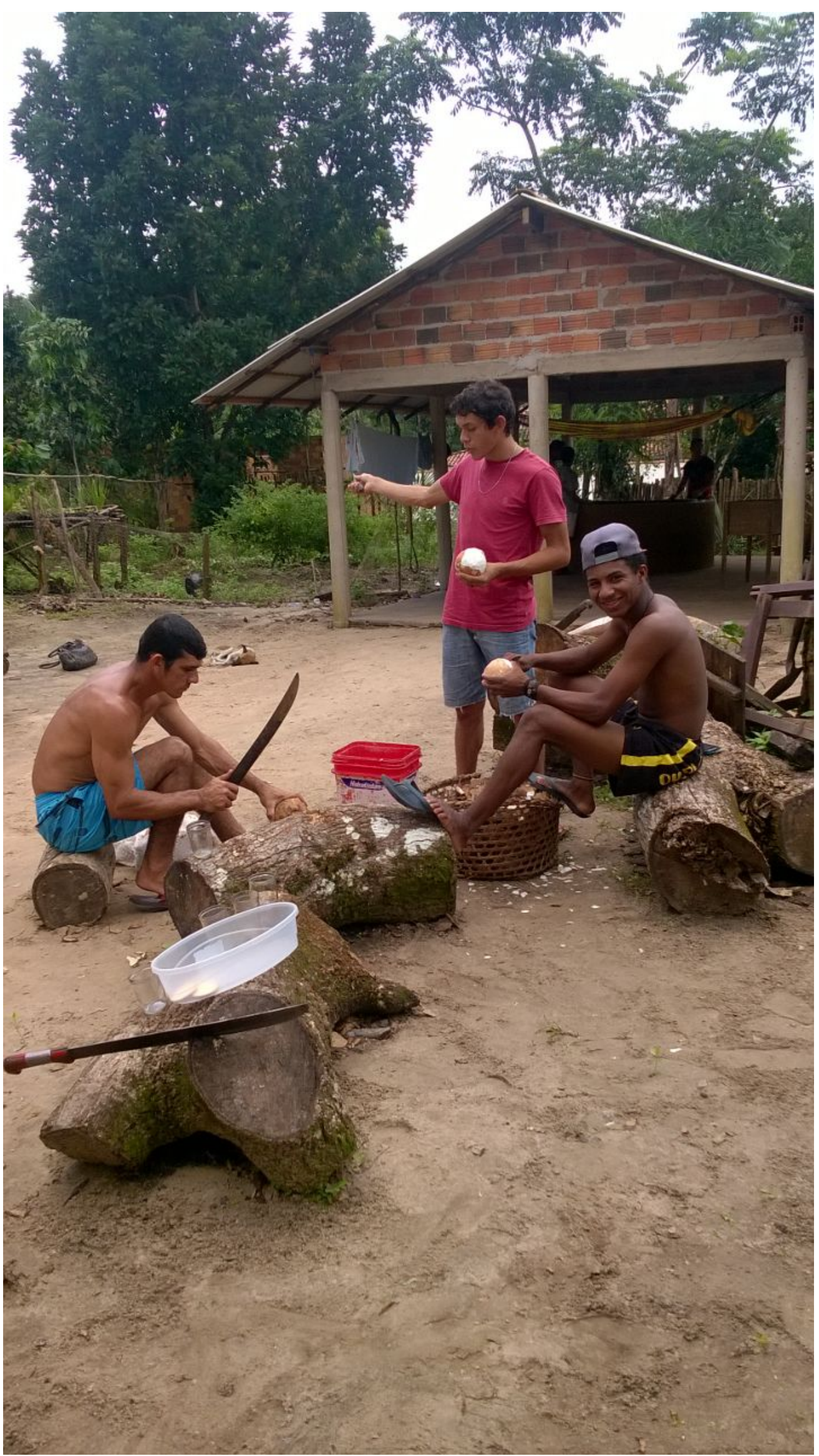




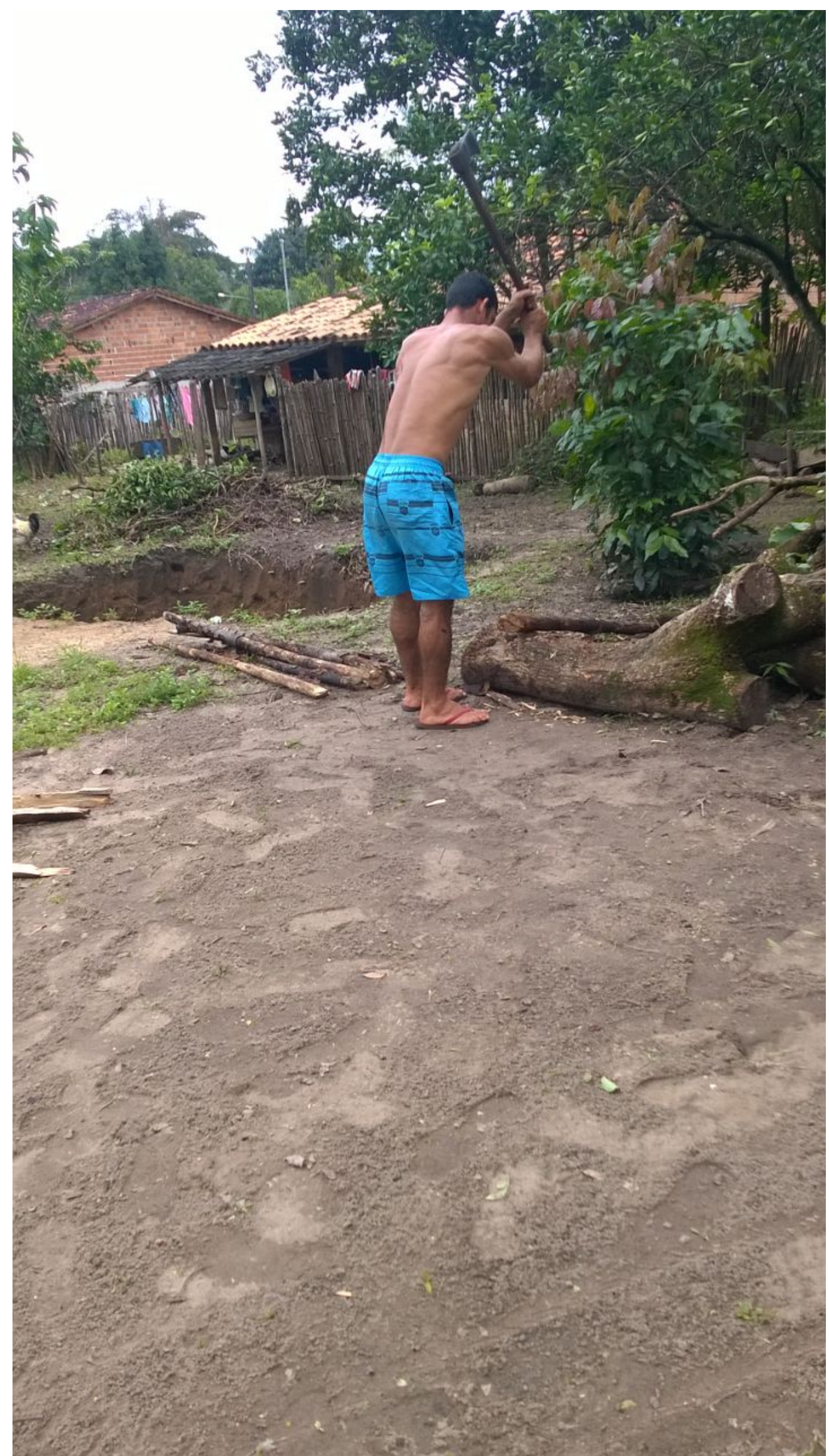




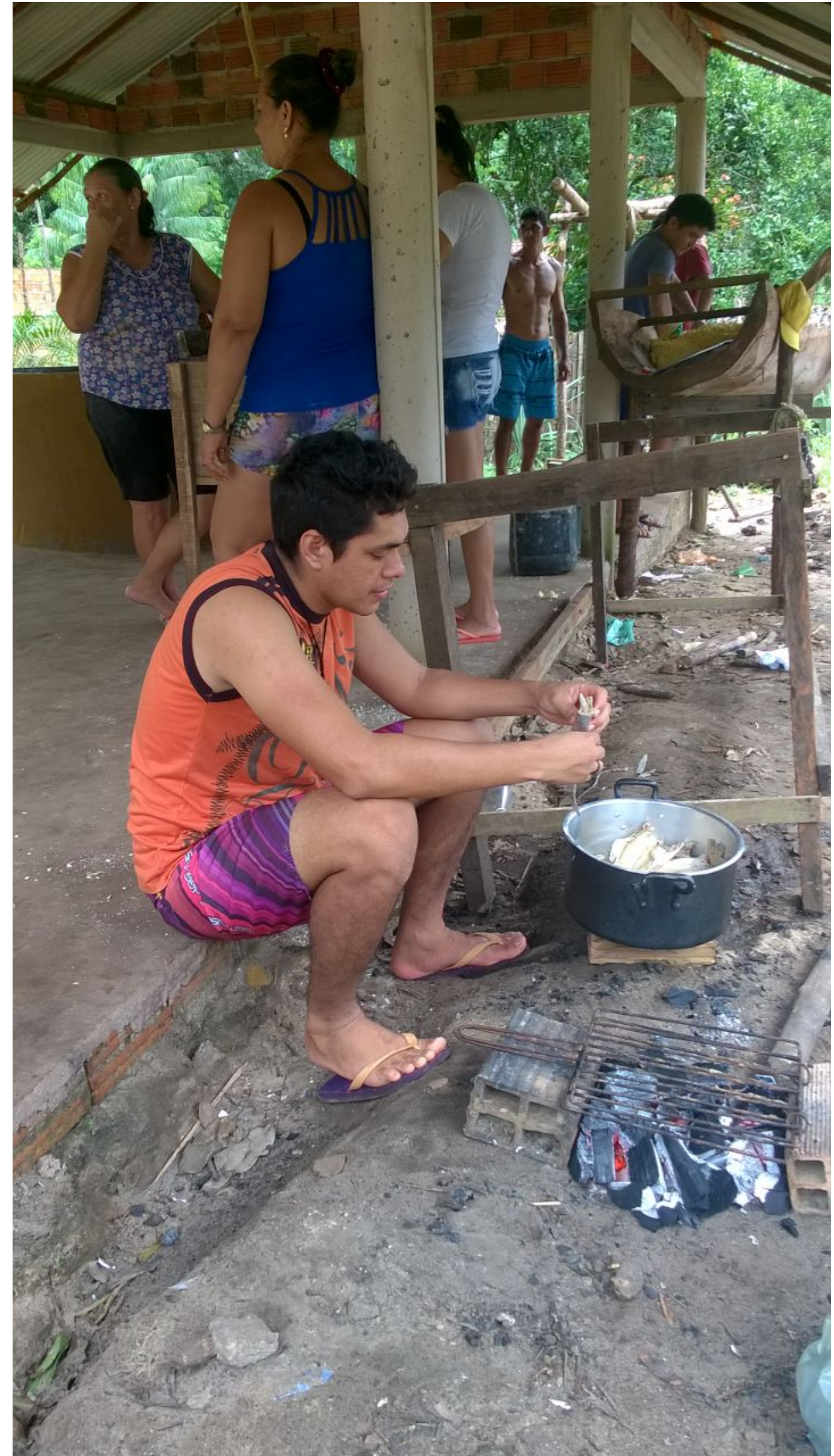




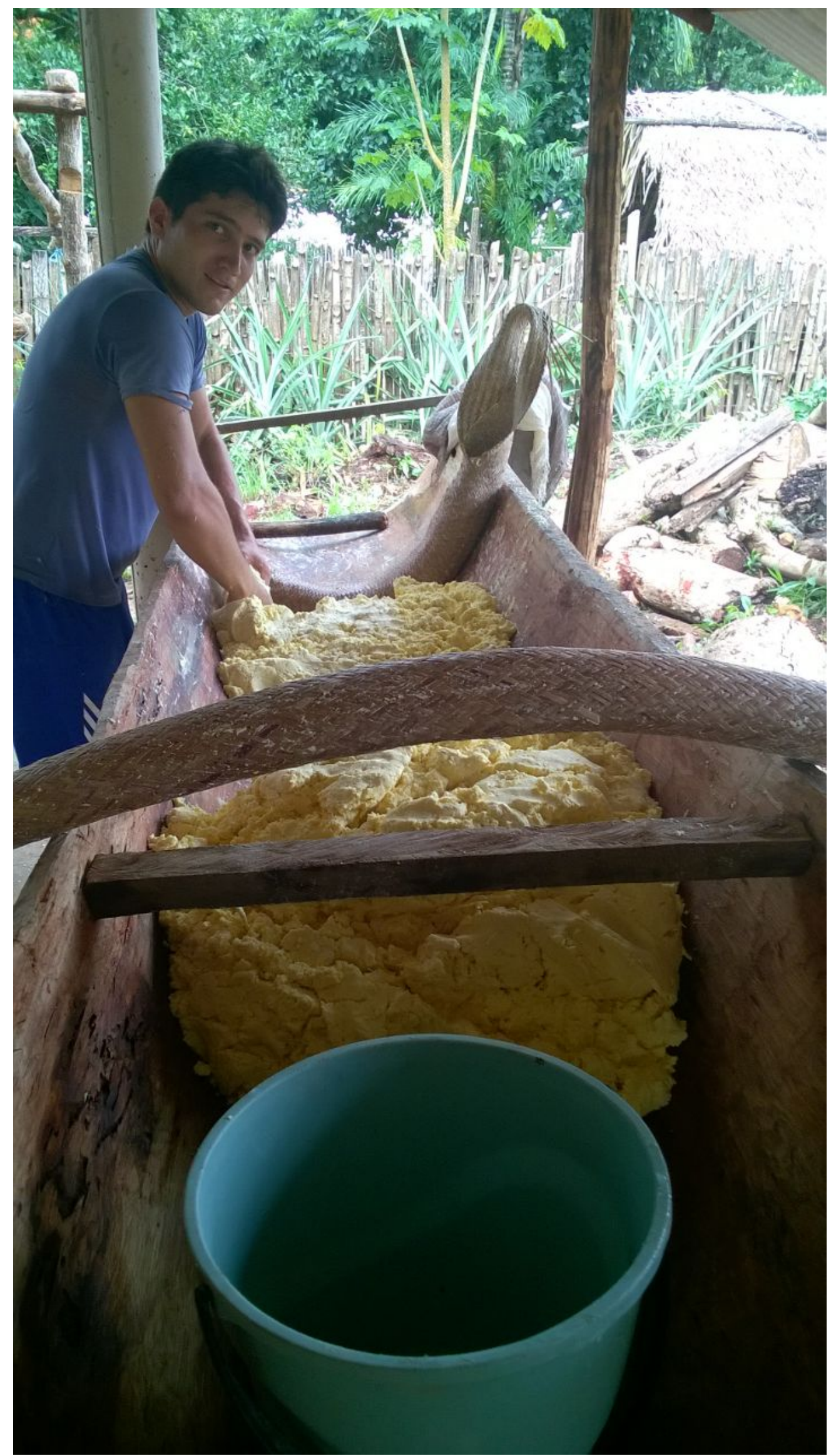




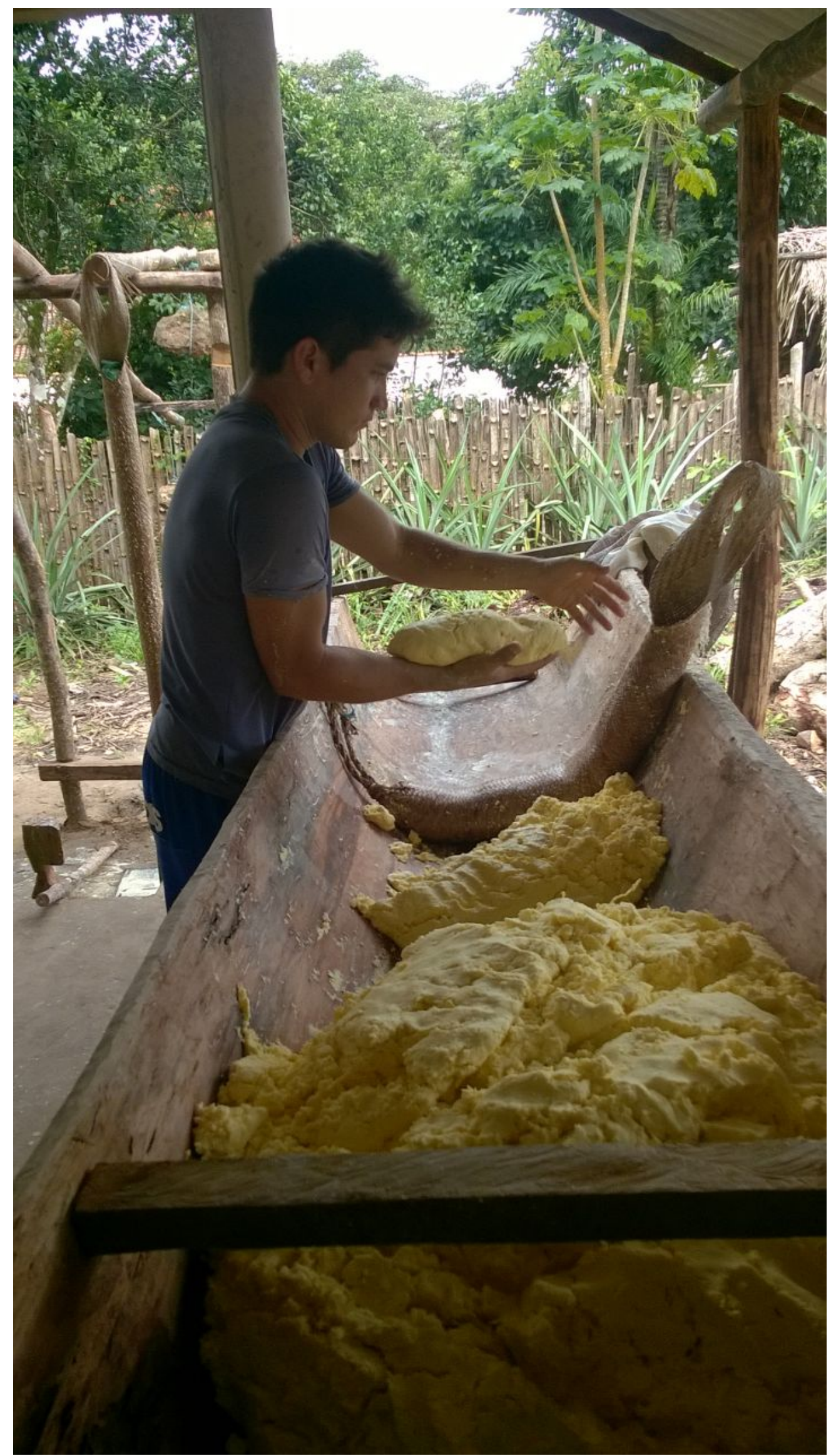




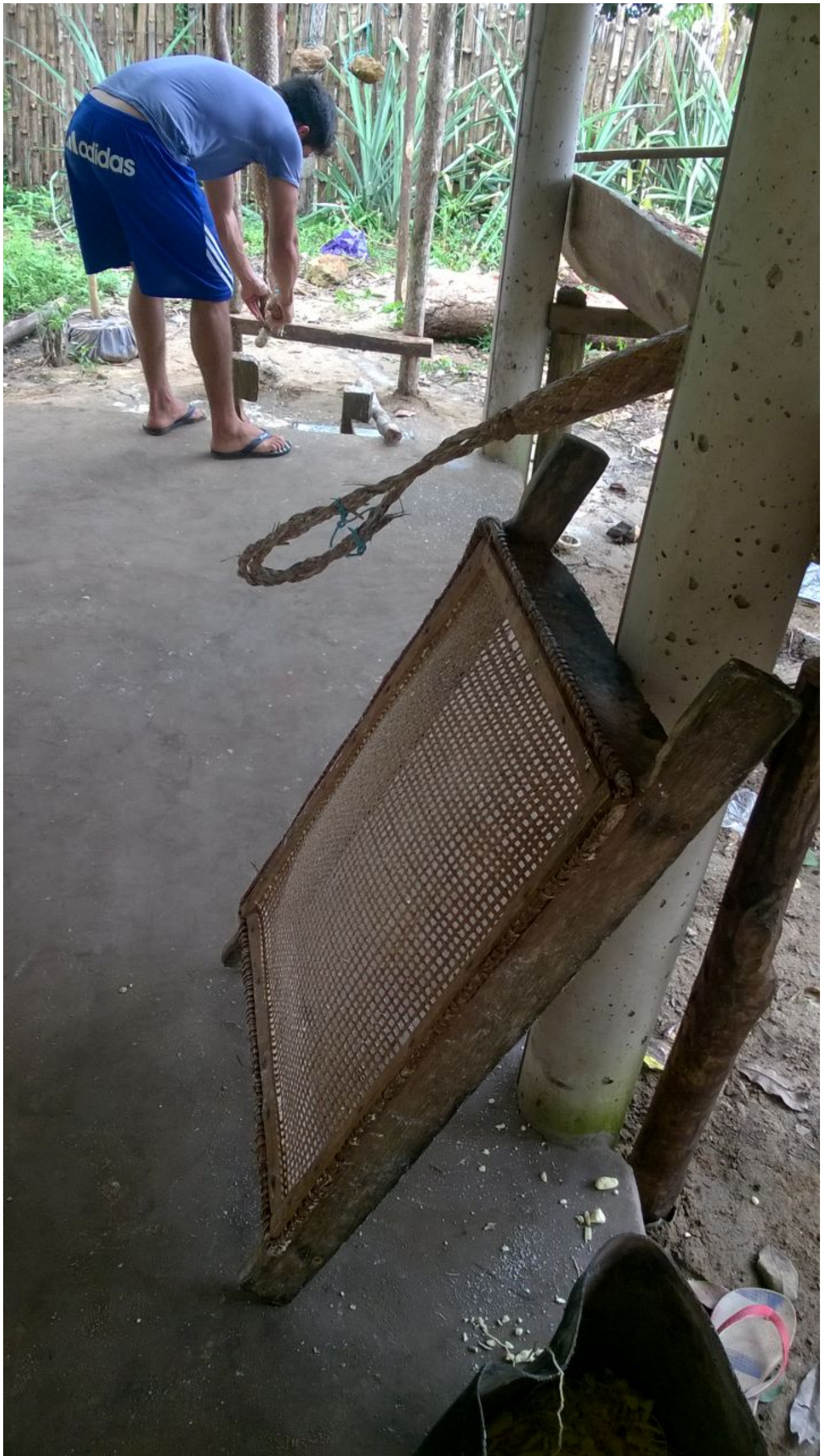




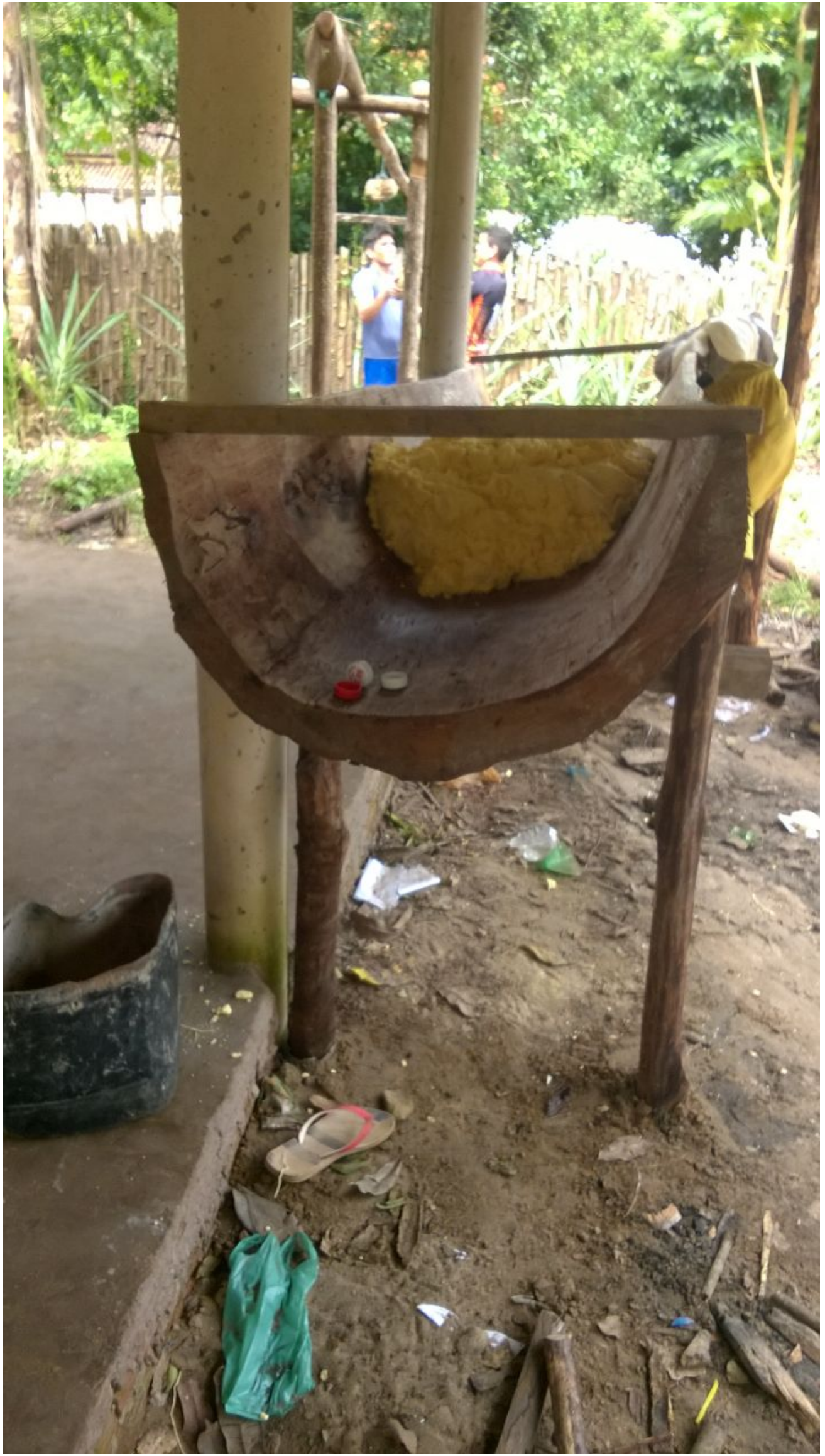




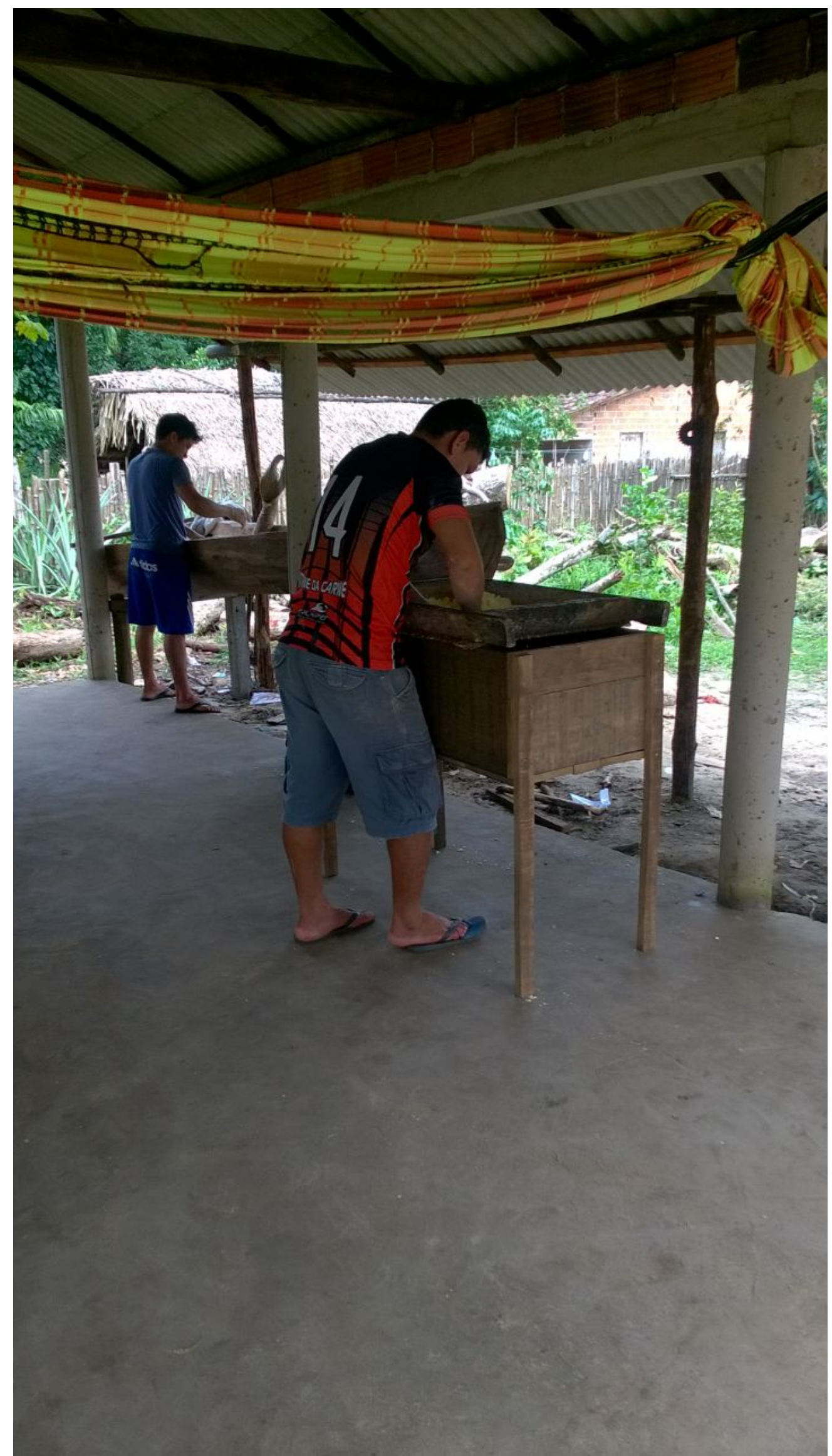




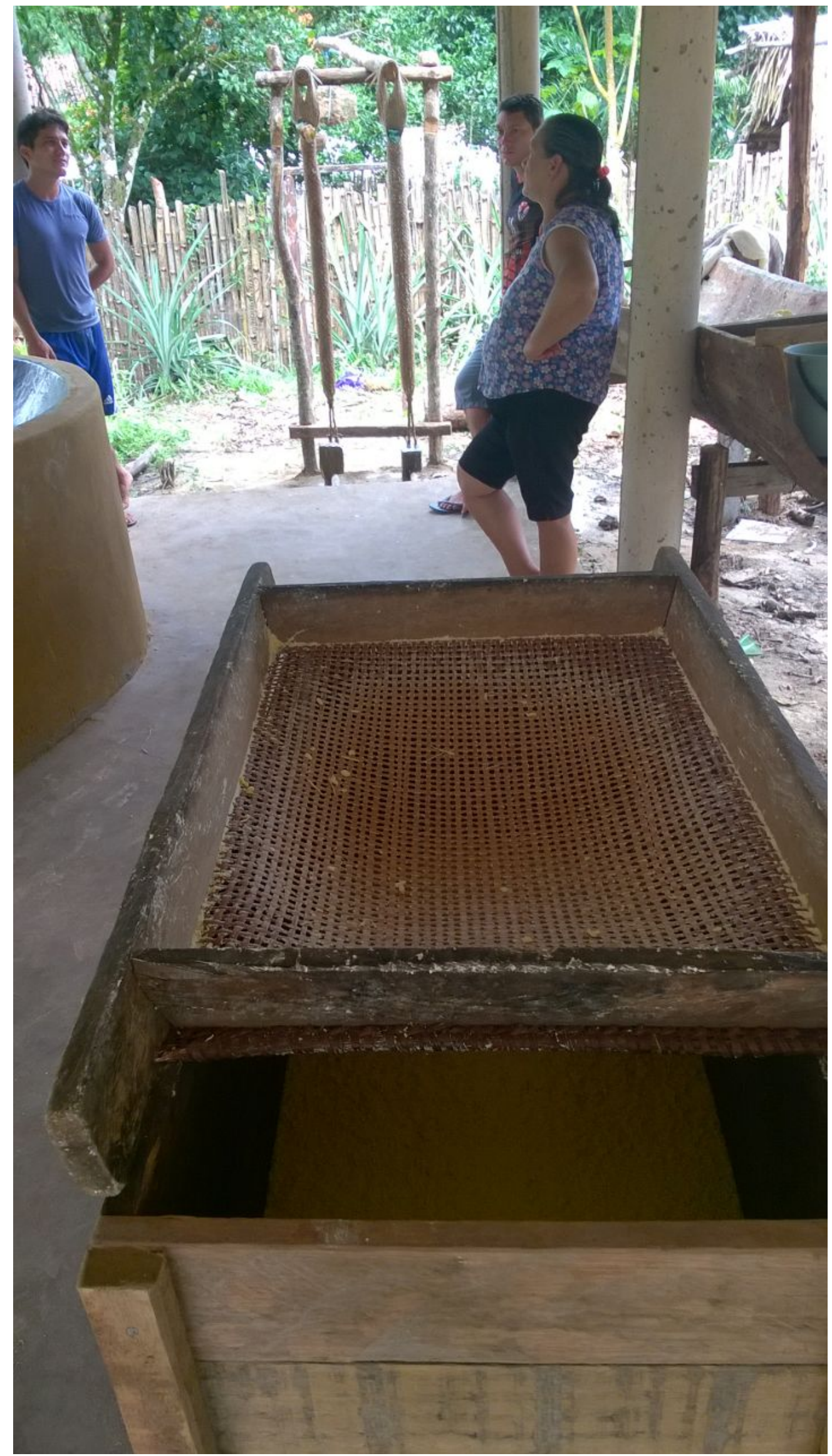



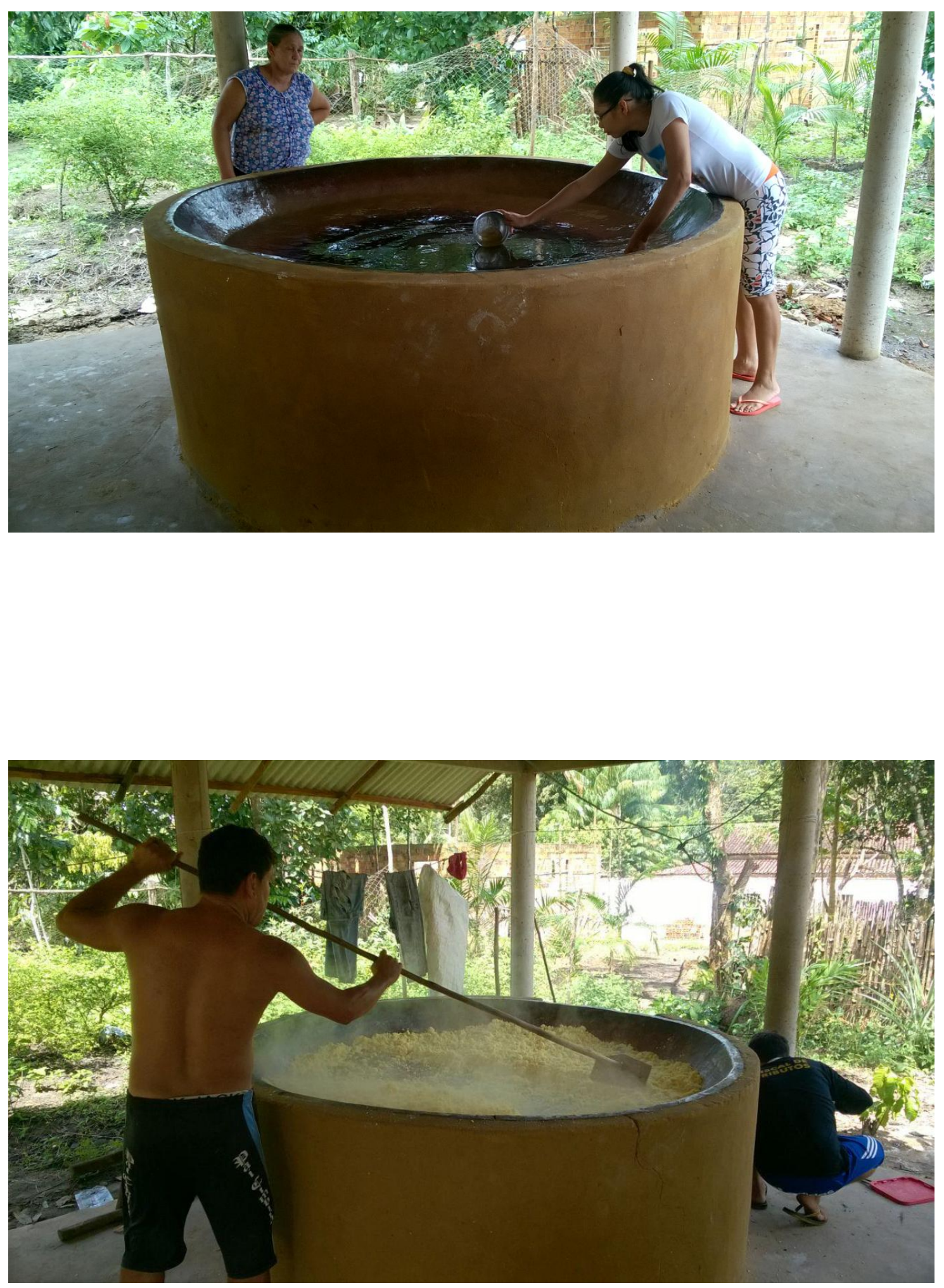

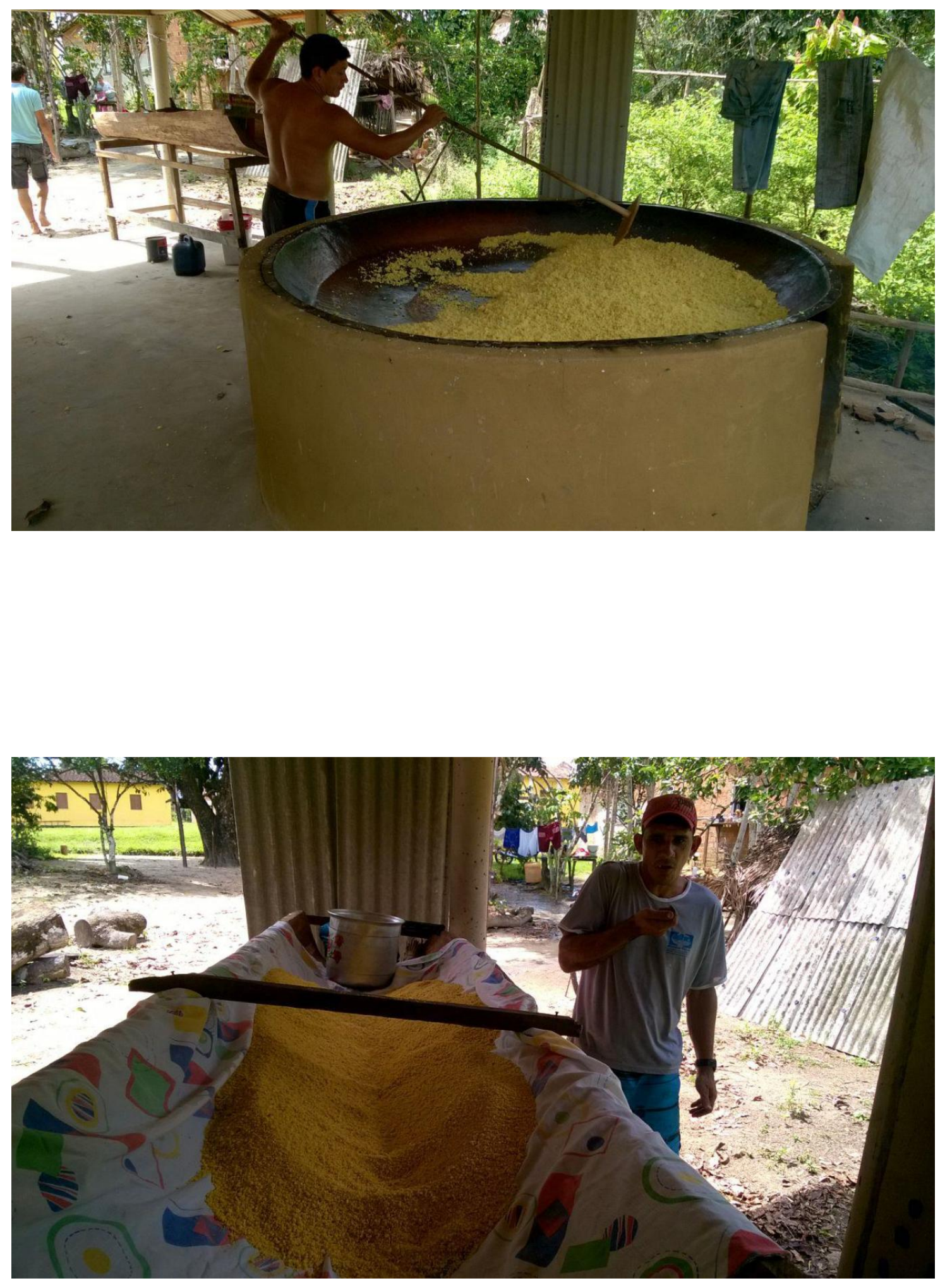